\title{
Perception of Social-Sexual Behavior and Workers' Productivity in Selected Banks in Nigeria
}

\author{
Stella $\mathrm{Mbah}^{1} \&$ Ossai $\mathrm{Abeh}^{1}$ \\ ${ }^{1}$ Department of Business Administration, Chukwuemeka Odumegwu Ojukwu University, Anambra State, \\ Nigeria \\ Correspondence: Stella Mbah, Department of Business Administration, Chukwuemeka Odumegwu Ojukwu \\ University, Anambra State, Nigeria.
}

Received: June 13, 2019

Accepted: July 4, 2019

Online Published: July 18, 2019

doi:10.5539/ibr.v12n8p15

URL:https://doi.org/10.5539/ibr.v12n8p15

\begin{abstract}
In this study, the effect of social sexual behavior on workers' productivity is examined from the perspective of individual managers, individual employees and work groups. A case study of banks in Delta State, Nigeria, is adopted to investigate the effect of social sexual behavior on workers' productivity from a different cultural perspective as obtainable in literature. A measure of workers' productivity and their interaction with components of social sexual behavior; sexual harassment and workplace romances, was obtained from 110 employees sampled from three banks within the study region through a questionnaire. Sex, age, marital status, education and employment status were adopted as moderating variables for the study. Multiple regression analysis was used in testing the hypotheses of the study. Result of this work reveal amongst others that sexually suggestive jokes or comments about a person's dress or body, made in their presence or directed towards them from a co-worker or customer could lead to demoralization of workers and poor interpersonal job performance between coworkers or of a worker towards a customer. The study further reveal that workplace romance could trigger jealousy among other employees, thereby leading to a failed interpersonal job performance and low productivity. The study recommends that organizations should clearly define their climate for social sexual behavior to both workers and customers through policies and sensitization with strict penalties given to defaulters.
\end{abstract}

Keywords: social sexual behavior, sexual harassment, workplace romance, workers' productivity

\section{Introduction}

\subsection{Introduction to the Study}

Organizational productivity requires emotional, psychological, healthy and physical well-being as well as great job satisfaction of workers. With the growing rate of romantic relationships, especially between employees of the same organization, one litmus test of organizational productivity is social sexual behavior. While some employees from an individual perspective perceive work place romance as harmless fun and job satisfying, organization managers at various levels opine that this behavior must be eliminated to ensure maximum employee performance. Aquino, Sheppard, Watkins, O'Reilly, \& Smith, (2014) note some social sexual behaviors as, gentle touching, complimenting physical appearance, sharing sexual stories and topics. Other forms of social sexual behavior which could make for a hostile work environment because of their intimidating, degrading, humiliating and offensive nature are; gender harassment, unwanted sexual attention.

As a form of social sexual behavior, work place romance is a consensual sexual relationship between two members of the same organization based on mutual attraction Pierce \& Aguinis, (2009) Pierce, Karl, \& Brey, (2012). From the sexual harassment perspective, women tend to show negative effects such as job stress, negative mood, long term anxiety, fear, poor interpersonal performance, eating disorder more than men who hardly report cases of these harassment as stressful or anxiety provoking Penn, (2014), though they are more likely to result to drug abuse and alcoholism Kime, (2014). However, research also shows higher negative effect of sexual harassment for men who are gay, in the military or against feminism Vogt, Pless, King, \& King, (2005). Furthermore, recent observation and research show that social sexual behavior most especially sexual harassment could come from other members outside an organization such as customers or clients. 


\subsection{The Study Problem}

Despite the gain of job satisfaction of individual workers from work place romance, organizations still view this in the same light as sexual harassment. For this reason some of them put up a very strict organizational climate. Notwithstanding, everyday observation and empirical data reveal that employees continue to find ways to relate with one another as sexual beings. This study aims to prove the relationship; whether positive or negative between social sexual behavior and workers' productivity in selected banks in Delta State, Nigeria. In this study, individual employees, individual managers and work groups' view of how social sexual behavior affects workers' productivity is ascertained. Banks are used as case study for this study to provide a perfect organizational environment where the legal definition of sexual assessment by equal employment opportunity commission (EEOC) can be appraised, considering that harassment could come from customers or clients and that the victim could be anyone affected by the act, not the target. Furthermore, with the promise of public private partnership to boost economic growth of Nigeria, this study used corporate private organization; banks, whose productivity have a great positive effect on the growth of Nigeria's economy.

Individuals, work groups and managers of organizations who are enthusiastic about improving organizational growth and productivity will benefit from this research work by understanding how various social sexual behavior which they might possess or exhibit in future affects their productivity, productivity of their victims and the organization at large. Results of this research would also provide the top hierarchy of organizations with a blue print to establish policies that would foster an organizational climate that reflects their tolerance level of social sexual behavior.

This study was guided by the following research questions:

1. What is the extent of the association between sexual harassment and worker's performance in an organization?

2. What is the extent of the interaction between workplace romance and workers' performance in an organization?

\subsection{The Study Objectives}

The study examined the perception of social sexual behavior and workers' productivity in selected banks in Nigeria. The specific objective include;

1. To ascertain the effect of sexual harassment on workers' productivity.

2. To determine the extent of the relationship between workplace romance and workers' productivity.

\subsection{Hypotheses}

This study was guided by the following null hypotheses

\section{Hypothesis One}

Ho: $_{1}$ : Sexual harassment has no significant effect on worker's performance.

\section{Hypothesis Two}

$\mathbf{H o}_{2}$ : Workplace romance has no significant effect on worker's performance. 


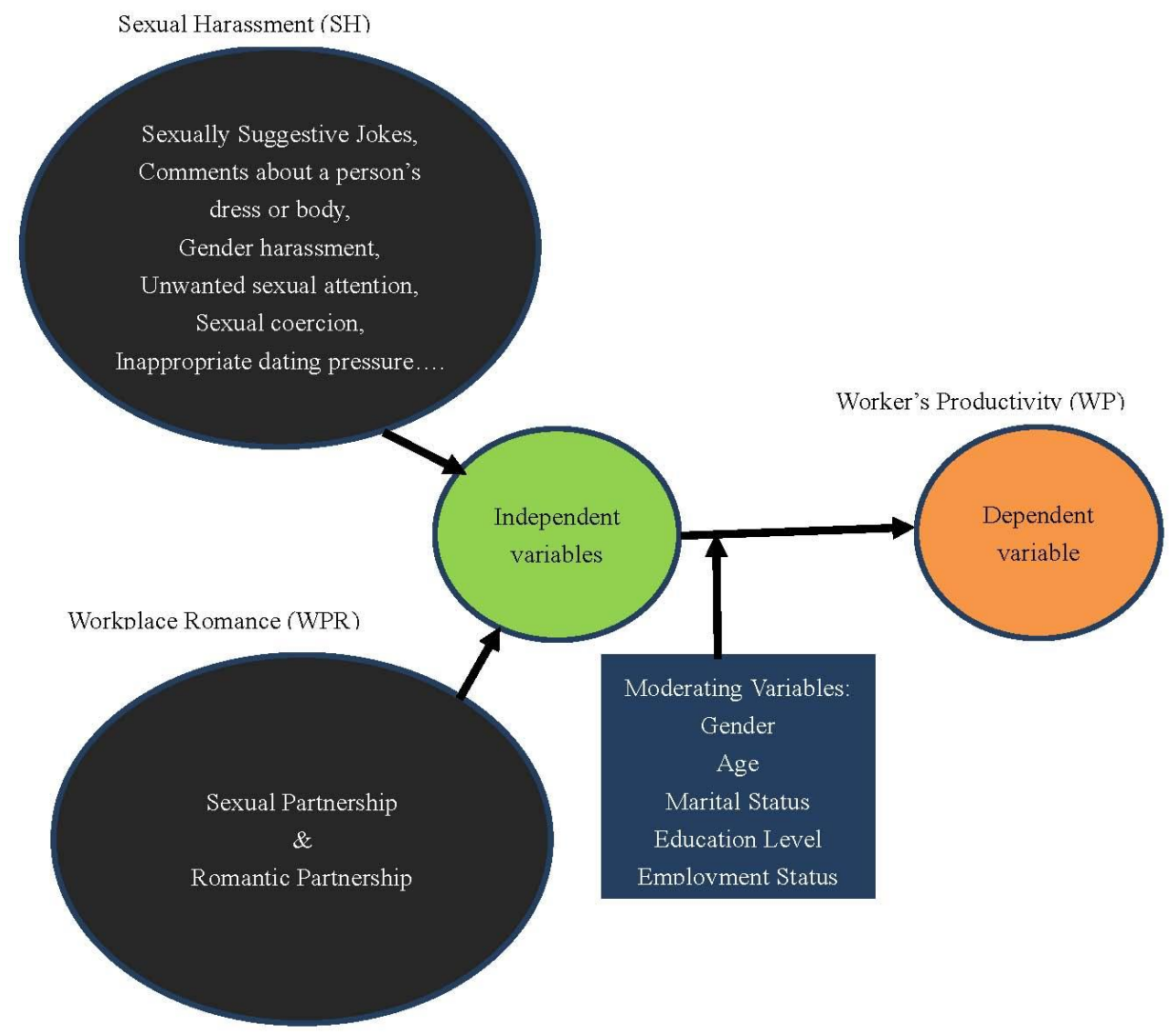

Figure 1. Conceptual framework

\section{Review of Related Literature}

Despite the popularity of social sexual behavior over the last decades and its perceived importance in organizational productivity, existing literature still lack empirical evidence to back this up in a constantly changing social world. A lot of existing literature on social sexual behavior are opinion papers. To the best of the researchers' knowledge, most of the existing empirical literature were conducted decades ago when research on the concept began and might not suit the present economic and social perception of things. Notwithstanding, some recent empirical studies still exist. Merkin, (2008) examined the effects of sexual harassment on overall turnover intentions, absenteeism and job dissatisfaction. The study sample was made up of 8018 employees in three countries of Latin America, chosen by the International Labour Organization. Multivariate and logistic regression methods were employed in the study. Age, gender, education, marital status and race were employed as moderating variables. Result of the study revealed that though employees who were sexually harassed showed tendency of significant turnover intentions and absenteeism which are the most costly outcomes of sexual harassment, they did not experience increased job dissatisfaction. In line with the indifferent view of job dissatisfaction from this result, Berdahl \& Aquino, (2009) examined the view of employees of; manufacturing firms, community service and universities, on their exposure and acceptance of social sexual behavior. The extent to which these behavior affects their psychological wellbeing was also examined. They study employed descriptive statistics and regression in analyzing the data acquired with a questionnaire. A total of 1238 respondents mostly populated by women across the three sectors of manufacturing, community services and university participated fully in the survey. About half of the population attested to exposure to sexual behavior within the last two years as of the time of the study. Though most respondents, both male and female attested to having fun with sexual behavior at work, the model of the authors predicted a negative effect on employee productivity and work in general.

Away from a general employee view of sexual harassment, Biggs, Matthewman, \& Fultz, (2012) investigated the views of individual managers and employees on exposure to workplace romance. They further ascertained how these views would reflect in creating organizational policies. Qualitative research was used to generate data from 36 respondents comprising of 21 employees and 15 managers in the US and the UK. From their result, it was 
concluded that organizational policies should accommodate workplace romance to some extent and not abolish it entirely. In the light of mild organizational policies that would accommodate workplace romance, Verhoef \& Terblanche, (2015) studied the effect of dissolved workplace romance on the psychological functioning and the productivity of involved employees. The study followed a qualitative research approach in conducting a word and content analysis that covered employees' experiences and productivity psychological functioning in the workplace amidst a relationship breakdown. They found out that, in general, a breakdown of workplace romance would impact a negative psychology on the productivity of the employees involved, though the negative impact would vary from person to person and time.

From a diverse cultural perspective, Merkin \& Shah, (2014) compared the impact of sexual harassment on various factors; job satisfaction, turnover intentions and absenteeism, that could affect employee performance in different working climates provided by Pakistan and the US. Copies of questionnaire were used as the key instrument for collecting data. The study drew samples from 146 health workers located in four cities of Pakistan and 102 students of New York in the US. Regression analysis was employed in testing the study hypotheses. From the result of the study, employees that experienced sexual harassment had greater dissatisfaction, turnover intentions and absenteeism in both countries. Though the rate of job dissatisfaction and absenteeism was higher for Pakistani employees than the US, most of the employees, especially women desist from direct approach in addressing sexual harassment so as to preserve certain cultural norms.

With the increasing perception of women being the core victims of sexual harassment, Idris, Adaja, Audu, \& Aye, (2016) studied the causes and effects of sexual harassment on the performance of female employees in selected organizations in Kogi state, Nigeria. Data for the study was gotten primarily from 60 respondents using a questionnaire. The study reported rank difference to be the major cause of sexual harassment and it negative effect on the performance of female employee. Low ranked women were mostly reported to be victims of sexual harassment.

Most existing literature have focused on examining how sexual harassment as a key component of social sexual behavior has affected workers productivity with little focus on workplace romance. This study looks critically at both sexual harassment and workplace romance as components of social sexual behavior. This study is also designed to accommodate scenarios of social sexual behavior not just between workers of the same organization studied but involving customers and clients of the organization. Unlike most existing studies, the study population is divided into clusters of individual mangers, individual employees and work groups, to ascertain their perceived relationship between the variables of social sexual behavior discussed and workers' productivity.

Since culture plays a large part in what constitutes sexual harassment which is a key component of social sexual behavior, this work is carried out in a location; Delta State, Nigeria, different from what is obtainable in most existing literature.

\section{Study Methods}

\subsection{Population and Sample}

In this study, the survey research design was employed to investigate the perception of social sexual behavior and its effect on workers' productivity in delta state, Nigeria. This study was centered on three selected corporate organizations; first bank, fidelity bank, and union bank, randomly selected from three senatorial districts in Delta State, Nigeria. A total of 140respondents; 90employees and 50 customers, randomly sampled from the three selected corporate organizations was used as the study's sample size. Fifteen male and female employees belonging to the senior and junior rank were purposively sampled from each of the three selected organizations. The senior rank employees comprised of managers and heads of different work groups. Based on the sample size of the study, 140 copies of questionnaire were distributed to the selected respondents, out of which 110(78.6\% response rate) copies comprising of response from 90 (100\% response rate) employees and 20 (40\% response rate) customers were found relevant for the study.

Data obtained were presented using the frequency tables and percentage method. Multiple regression was used in testing the hypotheses. 
Table 1. Representation of study sample

\begin{tabular}{lll}
\hline & Frequency & Percent \\
\hline GENDER & & \\
Male & 56 & 50.9 \\
Female & 54 & 49.1 \\
Total & 110 & 100.0 \\
& & \\
AGE & & \\
20-30 years & 45 & 40.9 \\
31-40 years & 55 & 50.0 \\
41-50 years & 10 & 9.1 \\
Total & 110 & 100.0
\end{tabular}

MARITAL STATUS

$\begin{array}{llr}\text { SINGLE } & 58 & 52.7 \\ \text { Married } & 47 & 42.7 \\ \text { Separated/divorced } & 5 & 4.6 \\ \text { Total } & 110 & 100.0\end{array}$

EDUCATIONAL

QUALIFICATION

OND/NCE/O'LEVEL $53 \quad 48.2$

$\begin{array}{lll}\text { B.Sc./HND } & 47 & 42.7\end{array}$

M.Sc./MBA $\quad 10 \quad 9.1$

$\begin{array}{lll}\text { Total } & 110 & 100.0\end{array}$

\section{EMPLOYMENT}

STATUS

$\begin{array}{lll}\text { Senior Staff } & 30 & 27.3 \\ \text { Junior Staff } & 60 & 54.5 \\ \text { Customer } & 20 & 18.2 \\ \text { Total } & 110 & 100.0\end{array}$

\subsection{Sources of Data Collection}

Primary date sourced by the use of copies of questionnaire issued to study sample of the selected corporate organizations in Delta State was used in this work.

\subsection{Evaluation of the Study Variables}

Social sexual behavior and workers' productivity was measured using multiple regression analysis.

\subsection{Reliability of the Instrument}

A pilot study based on the test re-test method was adopted in confirming the effectiveness of the questionnaire in eliciting information required for the study. A value of 0.771 obtained from Cronbach-Alpha test revealed the research instrument to be reliable.

\subsection{Statistical Methods}

To examine the hypotheses and study objectives, SPSS program was used on the data collected with the questionnaire. Frequencies, means, standard deviations and multiple regression were the statistical methods employed. 


\section{The Results}

The results of this study are presented as statistical characteristics of the study variables and regression analysis of the hypotheses of the study as presented in Table 2 and 3 respectively.

Table 2. Statistical Representation of the study variables

\begin{tabular}{llll}
\hline & N & Mean & Std. dev. \\
\hline SH & 110 & 18.29 & 3.065 \\
WPR & 110 & 18.05 & 2.513 \\
WP & 110 & 20.28 & 3.186 \\
\hline
\end{tabular}

Table 3. Outcome of hypotheses testing

\begin{tabular}{llllll}
\hline Hypotheses & T & T.Sig. & $\begin{array}{c}\text { Outcome of } \\
\text { Ho }\end{array}$ & $\begin{array}{l}\text { Outcome of } \\
\text { H1 }\end{array}$ \\
\hline HO1 & 2.612 & .008 & Rejected & accepted \\
HO2 & 3.120 & .002 & Rejected & Accepted \\
& & & & \\
\hline
\end{tabular}

\section{Hypotheses One}

Multiple regression analysis was used to measure the productivity of workers in corporate organizations; banks. The relationship between sexual harassment $(\mathrm{SH})$ and workers' productivity was measured by the first five questions (1-5) in the questionnaire.

Result of the relationship between SH and WP as shown in table 3 indicates a lesser significant value of 0.008 at a significant level of 0.05 . As a result, the null hypotheses $\mathrm{H}_{0}$ was rejected while the alternative hypothesis $\mathrm{H}_{\mathrm{i}}$ was accepted.

$\mathrm{H}_{0}$ : Sexual harassment has no significant effect on workers' productivity.

$\mathrm{H}_{\mathrm{i}}$ : Sexual harassment has significant effect on worker's productivity.

\section{Hypotheses Two}

The relationship between work place romance and workers' productivity was measured by questions 6-10 in the questionnaire. Result of the test as shown in table 3 indicates a t-statistics value of 3.120 and lesser probability value of 0.002 at a significant level of 0.05 . As such, $\mathrm{H}_{0}$ being the null Hypotheses was rejected and $\mathrm{H}_{\mathrm{i}}$, the alternative hypotheses accepted.

$\mathrm{H}_{0}$ : Workplace romance has no significant effect on workers' productivity.

$\mathrm{H}_{\mathrm{i}}$ : Workplace romance has significant effect on worker's productivity.

\section{Conclusions and Recommendations}

\subsection{Conclusions}

The relationship between social sexual behavior; sexual harassment and work place romance, and workers' productivity of three corporate organizations in Delta State, Nigeria was examined in this study. Results from the study highlighted that a positive significant relationship exists between sexual harassment, work place romance and workers' productivity. From an individual employee and manager perspective, the study revealed that sexual harassments in the form of sexually suggestive jokes or comments about a person's dress or body, made in their presence or directed toward them could lead to demoralization of workers and poor interpersonal job performance between coworkers or of a worker towards a customer. This form of sexual harassment stress was judged to be mainly reported by women. The result obtained is therefore in line with EEOC definition of sexual harassment pertaining involvement of customers or clients of an organization.

Also revealed, is a possible loss of trust towards a coworkerif he/she dates a superior, mostespecially a supervisor. From the study, this type of work place romance tends to ignite the feeling of awkwardness and jealousy among other employees, thereby, leading to a failed interpersonal job performance and low productivity. 
Furthermore, workplace romance among members of a work group; creates a divided atmosphere by creating another cluster in the existing group, leads to employee distraction and reduce group creativity and intelligent thought process of handling tasks.

Nonetheless, workers that involve or empathize with workplace romance reported higher motivation, job satisfaction and increased productivity.

In general, individual employees, individual managers and work groups attest that sexual harassment affects a worker's emotional or physiological state, leading to job dissatisfaction and reduced organizational commitment. Even so, individual employees maintain an opposing view that it increases their personal productivity which is a function of organizational productivity.

\subsection{Recommendation}

Based on the result of this study, the following recommendations were proposed;

Organizations should strictly adhere to rules and criteria for reward, promotion, disciplinary actions and training schedule, to avoid bias as a result of granted or requested sexual favor. To further ensure this strictness, organizations should incorporate an approach that decreases the hierarchical distinction in leader-follower relations by involving followers in committees in charge of exercises that involves reward, promotion, and disciplinary and training actions of workers.

Just as some organizations have defined their intolerance for family work place relationships, organizations have to also clearly define with penalties, their climate for work place romance, sexually suggestive jokes and gossips.

Training and sensitization on organization policies should be given at intervals to workers and customers, so as to; reduce the possibility of sexual harassment through unhealthy interpersonal relationship, recognize and report cases of sexual harassment by individuals who are not even the sufferers. Alongside this, reliable channels for counselling should be provided when sexual harassment occurs.

\section{References}

Aquino, K., Sheppard, L., Watkins, M. B., O'Reilly, J., \& Smith, A. (2014). Social sexual behavior at work. Research in Organizational Behavior, 34, 217-236. https://doi.org/10.1016/J.RIOB.2014.02.001

Berdahl, J. L., \& Aquino, K. (2009). Sexual behavior at work: Fun or folly? Journal of Applied Psychology, 94(1), 34-47. https://doi.org/10.1037/a0012981

Biggs, D., Matthewman, L., \& Fultz, C. (2012). Romantic relationships in organisational settings. Gender in Management: An International Journal, 27(4), 271-285. https://doi.org/10.1108/17542411211244803

Idris, H., Adaja, J., Audu, S., \& Aye, G. (2016). Analysis of the Causes and Effects of Sexual Harassment on the Performance of Female Employees in Some selected Organizations in Kogi State, Nigeria. International Journal of Democratic and Development Studies (IJDDS), 2(2), 31-39. Retrieved from http://www.rcmss.com.

Kime, P. (2014). Incidents of rape in military much higher than previously reported. Retrieved June 6, 2019, from Vienna. VA: Military Times website:

https://www.militarytimes.com/2014/12/04/incidents-of-rape-in-military-much-higher-than-previously-rep orted/

Merkin, R. (2008). The Impact of Sexual Harassment on Turnover Intentions, Absenteeism, and Job Satisfaction:Findings from Argentina, Brazil and Chile. Journal of International Women's Studies, 10(2), 73-91. Retrieved from https://vc.bridgew.edu/jiws/vol10/iss2/7

Merkin, R., \& Shah, M. K. (2014). The impact of sexual harassment on job satisfaction, turnover intentions, and absenteeism: findings from Pakistan compared to the United States. SpringerPlus, 3(1), 215. https://doi.org/10.1186/2193-1801-3-215

Penn, N. (2014). “Son, Men Don’t Get Raped.” Retrieved June 6, 2019, from Gentlemen’s Quarterly website: https://www.gq.com/story/male-rape-in-the-military

Pierce, C. A., \& Aguinis, H. (2009). Moving beyond a legal-centric approach to managing workplace romances: organizationally sensible recommendations for HR leaders. Human Resource Management, 48(3), 447-464. https://doi.org/10.1002/hrm.20289

Pierce, C. A., Karl, K. A., \& Brey, E. T. (2012). Role of workplace romance policies and procedures on job pursuit intentions. Journal of Managerial Psychology, 27(3), 237-263. 
https://doi.org/10.1108/02683941211205808

Verhoef, H., \& Terblanche, L. (2015). The effect of dissolved workplace romances on the psychosocial functioning and productivity of the employees involved. Social Work, 5l(2), 287-310. https://doi.org/51-1-448

Vogt, D. S., Pless, A. P., King, L. A., \& King, D. W. (2005). Deployment stressors, gender, and mental health outcomes among Gulf War I veterans. Journal of Traumatic Stress, 18(2), 115-127.

https://doi.org/10.1002/jts.20018

\section{Copyrights}

Copyright for this article is retained by the author(s), with first publication rights granted to the journal.

This is an open-access article distributed under the terms and conditions of the Creative Commons Attribution license (http://creativecommons.org/licenses/by/4.0/). 